\title{
Integrated Healthcare in India - A Conceptual Framework
}

\author{
Ravinder Singh \\ Indian Council of Medical Research, New Delhi, India
}

Recent reports of healthcare reforms in India have reinforced the view that India's current healthcare system is not sustainable for its 1.25 billion population. An estimated 600 million people in India, many in rural locations, have little or no access to healthcare. Corruption in the medical regulatory agency makes it more imminent to introduce radical changes in our healthcare management system $[1,2]$. In India, both the Ministry of Health and Family Welfare and Ministry of AYUSH are responsible for healthcare. A huge network of primary healthcare falls under the Ministry of Health and Family Welfare; however, the role and coordination effort of Ministry of AYUSH with the former remains unclear. Even though the present political leadership is committed to highlighting the role of Ministry of AYUSH, its integration with health reforms needs special focus.

India faces a critical shortage of trained health professionals such as doctors, nurses, and allied healthcare workers [3]. The government has announced a new health policy that focuses on reducing malnutrition, improving the use of essential medicines, expanding immunization, modernizing public hospitals, and instituting a better tobacco control program. The government is also considering a holistic healthcare system that is universally accessible, affordable, and which dramatically reduces out-ofpocket health expenditures [4].

Earlier, the Union Health Ministry had planned to create a 'specialized cadre of healthcare workers for rural ar- eas' by instituting a 3-year-course in state universities Bachelor of Science in Community Health. However, this was rejected by the Indian Medical Association [5]. The major reason for rejecting this was the rationale behind differentiating rural from urban populations. The key to delivering good healthcare in rural areas without compromising quality is the biggest challenge. Majority of our modern medical fraternity and tertiary health facilities are concentrated in urban areas, which are often overcrowded with patients and healthcare workers alike. The solution lies in ensuring uniform health force in all areas. Most of the time spent in medical education (approximately 3 years), whether in medical colleges, ayurvedic colleges, homeopathic colleges, dental colleges or naturopathy colleges is dedicated to understanding the human body, its composition, physiology, biochemistry, microbiology, pathology etc. Only the last few months of this period is spent in learning the practical aspects of treatment with or without exposure to surgical techniques. We need to review our teaching curriculum and assess its impact on the overall health scenario in the Indian subcontinent. The burden of communicable and non-communicable diseases remains a major challenge for our health professionals. In fact, majority of such conditions or health problems can be prevented through lifestyle or dietary and behavioural modifications, which India can easily afford. India has, therefore, promoted Yoga internationally and is actively taking lead in showcasing the world that it not only

\section{KARGER}

E-Mail karger@karger.com

www.karger.com/aon
(C) 2016 S. Karger AG, Basel

0972-7531/16/0234-0197\$39.50/0
Ravinder Singh

Indian Council of Medical Research

ICMR Hqrs, New Delhi 110029 (India)

E-Mail drravindersingh@ rediffmail.com 
preaches but also practices. The recently held International Yoga Day on June 21 is a testimony to this. All these changes can be sucessful if the health workforce is trained to work in tandem with modern medicine. The structures of allopathic medical colleges, ayurvedic colleges, homeopathic colleges, dental colleges, naturopathy colleges remain drastically different, and call for a 'transformational change', not just an incremental change. The basic medical degree will need to combine all aspects of medical health, encompassing social, spiritual, mental and medical components of healthcare system (integration at ministry level and college level). Such doctors would be more closer to communities, holistic in nature, will focus on preventive and promotive aspects of health by delivering integrated solutions that combine modern medicine, alternative medicine, diet, behavior and yoga. Simpler solutions may emerge from simpler public health solutions such as Swach Bharat Abhiyan or the clean India campaign that can easily result in eradication or minimization of communicable diseases.

\section{References}

1 Trouble at the Medical Council of India, 2010, vol 375. www.thelancet.com.

2 News: Medical Council of India is corrupt, says health minister. BMJ 2014;349:g4762.

3 Deloitte: 2015 global health care outlook common goals, competing priorities. http:// www2.deloitte.com/content/dam/Deloitte/
global/Documents/Life-Sciences-HealthCare/gx-lshc-2015-health-care-outlookglobal.pdf.

4 Industry Report, Healthcare: India, The Economist Intelligence Unit, 2014.

5 The Hindu News: IMA Protests B.Sc Course in Community Health, 2015. 